\title{
EVOLUTION OF SOFT DRUSEN IN AGE-RELATED MACULAR DEGENERATION
}

\author{
J. P. SARKS, S. H. SARKS and M. C. KILLINGSWORTH \\ Sydney, Australia
}

\begin{abstract}
SUMMARY
The pathways by which soft drusen are formed are illustrated by representative clinical and clinicopathological cases. One type is derived from small hard drusen which first tend to aggregate into clusters and then fuse, forming larger deposits termed hard clusters. Breakdown of the hard drusen results in varying degrees of softening and confluence. These soft clusters may appear in middle age and, like the preceding hard drusen, remain a focal pathology. Soft clusters commonly lead to the atrophic form of age-related macular degeneration. Another type of soft drusen is formed from membranous debris as part of a diffuse disturbance of the retinal pigment epithelium. These membranous soft drusen first appear in the seventh decade and are commonly associated with choroidal neovascularisation.
\end{abstract}

Several population-based studies have confirmed an association between drusen and the more severe manifestations of age-related macular degeneration (AMD). Especial risk attaches to large, soft or confluent drusen. ${ }^{2.3}$ Clinical grading systems have therefore been proposed, based on graticules placed over $35 \mathrm{~mm}$ colour fundus photographs, to estimate drusen extent. distribution and size. ${ }^{3-5}$

The characteristic most difficult to grade on fundoscopy is drusen type. There is agreement that small hard drusen are round, yellowish deposits with well-defined borders. They are not visible in the fundus until $30-50 \mu \mathrm{m}$ in diameter and are more difficult to see in fair fundi. The alternative designation of drusen as soft is based on poorly defined edges and a softer appearance of their contents, characteristics which in turn appear related to drusen size. Thus in the Wisconsin grading system' drusen up to $63 \mu \mathrm{m}$ in diameter were classified as hard distinct. Soft drusen were those over $125 \mu \mathrm{m}$ in diameter and even those 63-125 $\mu \mathrm{m}$ in diameter that had a visible thickness. These

From: Department of Ophthalmology. Lidcombe Hospital. Sydney. Australia.

Correspondence to: Dr John Sarks, 15 Parnell Street. Strathfield. NSW, Australia 2136. soft drusen were further categorised as soft distinct if they had a uniform density, nodular surface and sharp margins, while those with a decreasing density from centre to periphery and fuzzy edges were termed soft indistinct. In the Macular Photocoagulation Study ${ }^{2}$ 98\% of patients in whom the drusen were categorised as soft according to their ill-defined margins, had drusen that were also over $50 \mu \mathrm{m}$ in diameter.

This association between drusen size and drusen consistency is better appreciated on fluorescein angiography and pathological examination. Hard drusen can be shown to break down, often after first aggregating into clusters that ultimately become large soft drusen with a granular structure. However, there are other soft drusen which appear to be composed of membranes. ${ }^{6}$ The aim of this paper is to discuss the formation of these soft drusen in relation to the evolution of $\mathrm{AMD}$, as a step towards achieving a satisfactory drusen classification.

\section{MATERIALS AND METHODS}

The clinicopathological findings in five cases representative of the lifecycle of drusen are reported. Observation of these five patients commenced between 6 and 14 years before death and an ocular examination including fundus photography had been performed at intervals of $1-3$ years. Three of the patients also had fluorescein angiography performed. The eyes were obtained post mortem and prepared for electron microscopy according to techniques previously described. ${ }^{6}$ Two additional younger patients who are still under observation (cases 3 and 4) are included without pathological correlation as they better illustrate certain of the clinical features described.

\section{Definition of Drusen}

In this report drusen are regarded histopathologically as deposits of extracellular material lying between the basement membrane of the retinal pigment epithelium (RPE) and the inner collagenous zone of Bruch's membrane. This excludes material internal to the basement membrane as seen in basal laminar drusen, which is a dominantly 
inherited dystrophy of small, radially arranged drusen ${ }^{7}$ it also excludes diffuse thickening of the basal laminar deposit (BLD) as occurs in advanced AMD. Also excluded are reticular drusen, ' a yellowish lobular pattern commonly observed in the outer macular region that does not fluoresce and is best seen in blue or red-free light. ${ }^{8}$ No debris has been found to correspond with this picture and, since it resembles the mosaic appearance described in eclampsia that has been attributed to insufficiency of the choroidal circulation, ${ }^{9}$ the term pseudodrusen seems most appropriate at the present time.

\section{Definition of $A M D$}

The histopathological definition of AMD, as determined in a previous clinicopathological study, ${ }^{10}$ was the presence of a continuous layer of the BLD under the macula. Subsequent electron microscopic observations ${ }^{11}$ demonstrated that occurring in association with the BLD, which comprised mainly banded material in the early stages of degeneration and amorphous material in the later stages, there was a build up of membranous debris on both aspects of the RPE basement membrane. Evidence of this diffuse disturbance at the level of the RPE was evident in the present study in the eyes with soft drusen (cases 5, 6 and 7).

\section{RESULTS}

\section{Case 1. Small Hard Drusen with Dispersion of Contents}

A 61-year-old man was seen 6 months before he died from a myocardial infarct. He had suffered from epilepsy, alcoholic cirrhosis of the liver and heart failure. Vision was $6 / 6$ in both eyes. Fundoscopy had shown a dark eyeground with mottled hypopigmentation at the posterior pole, but individual drusen were not conspicuous. That this hypopigmentation represented numerous drusen was more clearly seen in red-free light and especially on fluorescein angiography (Fig. 1). The fact that many of the drusen appeared indistinct on fundoscopy was thought to be due to their small size, most being discrete and 30$75 \mu \mathrm{m}$ in diameter although several larger lobulated deposits were also present.

On pathological examination there was no BLD or membranous debris in this eye and the RPE showed only mild distension with lipofuscin or slight attentuation over the larger drusen. However, almost the entire surface of Bruch's membrane was covered with small hemispherical drusen (Fig. 2). The smallest appeared as a row of rounded elevations of the inner surface of Bruch's membrane, mostly about $1 \mu \mathrm{m}$ wide (Fig. 3). Referred to as microdrusen, they passed beneath the larger drusen. Similar but less numerous excrescences projected from the choroidal aspect of the membrane. These microdrusen were structureless and extremely electron dense, but in the larger drusen the amorphous contents became dispersed and more electron lucent. The dispersion generally started in the base of the drusen, but as long as a rim of the original deeply staining, electron-dense material remained around the margin, the drusen retained sharp edges. Where this rim disappeared, the base of the druse spread out along Bruch's membrane (Fig. 3).

Most of the drusen were about 16-20 $\mu \mathrm{m}$ high or little taller than the RPE itself and so probably formed at much the same time. Fusion of several drusen resulted in a small number of larger lobulated deposits (Fig. 2-iii), their shape suggesting that the drusen retained a plastic rather than a soft consistency so that spread occurred into the retina rather than along Bruch's membrane. Where dispersion had occurred in these larger deposits, the individual drusen were no longer recognisable. However, the preservation of a rim of amorphous material meant that the deposit demonstrated a series of nodular surface elevations and well-defined margins (Fig. 2-iv). Macrophages beneath Bruch's membrane were sparse and no thinning of Bruch's membrane was observed.

\section{Case 2. Clustering, Fusion, Differential Breakdown}

The patient was a normotensive 74-year-old man suffering from peripheral vascular disease and dementia. At age 76 years vision was still $6 / 6$ but thereafter the patient became increasingly difficult to examine and died at age 81 years. The small hard drusen in this patient were not as numerous as in case 1 but demonstrated a tendency to occur in clusters (Fig. 4). In some clusters the individual drusen were still recognisable; in others they appeared fused into a single larger deposit.

The tendency to clustering was more apparent on histopathological examination as the intervening drusen were of ten too small to be seen clinically (Fig. 5). Those clusters in which the fused drusen were all of similar size had a nodular surface and sharp margins (Fig. 6). However, in this older patient the fused drusen were often of different ages and the contents remained unmingled. In the pair of fused drusen illustrated in Fig. 7 the small hard druse is intact but the larger druse has spread along Bruch's membrane and its contents have separated into irregularly shaped fragments. Some of the fragments would dovetail together, suggesting the loss of compactness may have occurred post mortem, but a differential rate of breakdown nevertheless appears to exist and to be a function of the state of the RPE, which is very attenuated over this broken-down druse. Similar changes were noted within clusters or drusen. This patient therefore demonstrates an initial fusion of small hard drusen into larger deposits of similar hard appearance, followed by a differential breakdown as a prelude to softening of the cluster. This sequence is illustrated clinically by the following two patients who are still under observation.

\section{Case 3. Hard Clusters Resulting from Fusion of Small Hard Drusen}

A 31-year-old man first presented with numerous drusen as an incidental finding, vision being unaffected. The drusen were most numerous on the temporal side of the fovea and many were surrounded by a reddish halo (Fig. 8). Despite having a soft appearance, on fluorescein 

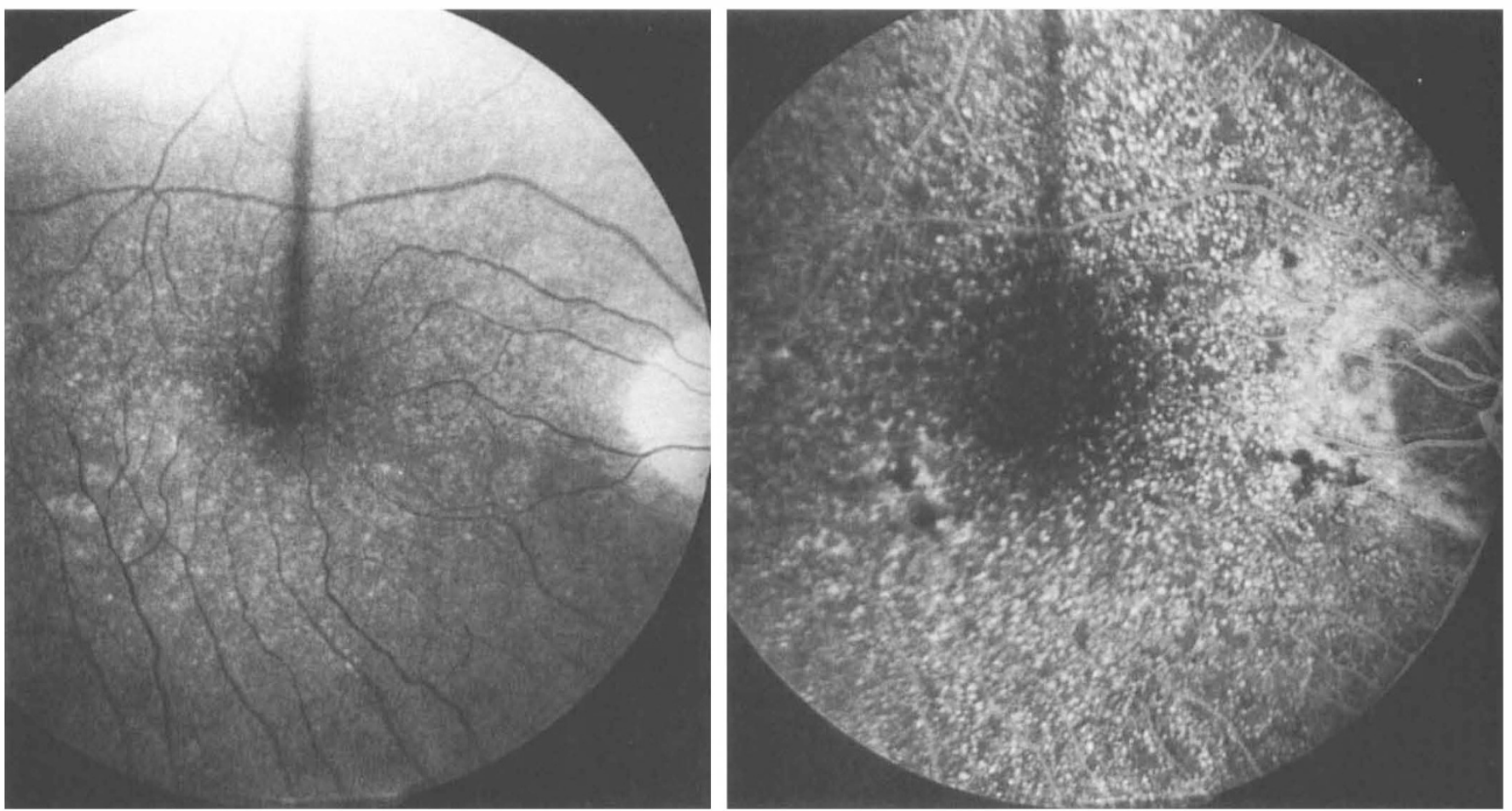

Fig. 1. Case 1. Red-free (left) and fluorescein angiogram (right) of eve of a 61 -vear-old man photographed 6 months before death. The posterior pole show'ed mottled hypopigmentation, caused by many relatively inconspicuous drusen. The majority were of the small hard variety and 50-75 $\mathrm{mm}$ in diameter, although below and temporal to the fovea there vere several larger deposits up to 150 um across. Fluorescein angiography confirmed mrraids of discrete hard drusen as small as $30 \mu \mathrm{m}$.

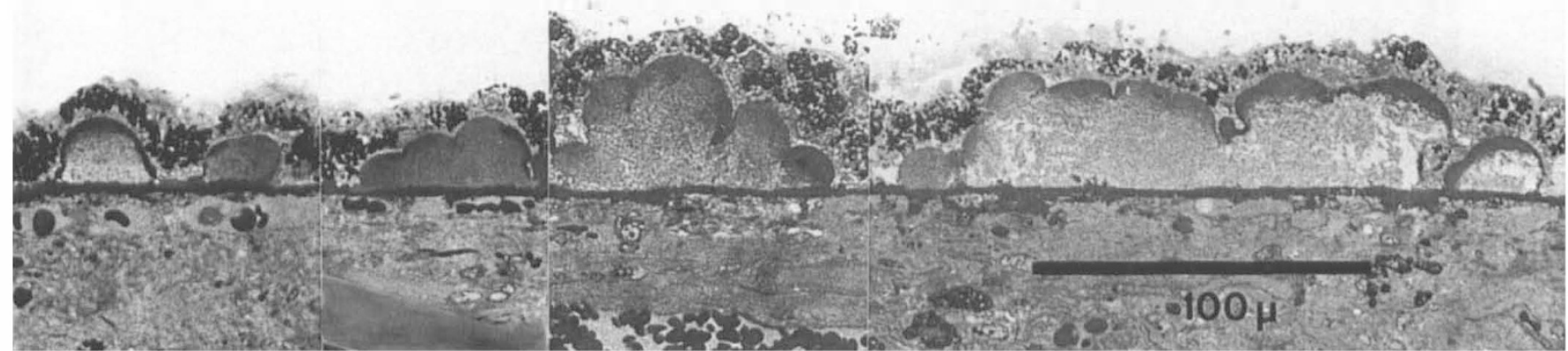

Fig. 2. Composite photograph of different semithin sections from the eye shown in Fig. I. Almost the entire surface of Bruch's membrane was covered with drusen of the small hard type. (i) The majority were small discrete hard drusen of varying electron density, little taller than the height of the retinal pigment epithelium (RPE). Higher magnification is shown in Fig. 3. (ii) Larger druse with lobulated surface and sharp margins, resulting from fusion of a drusen cluster. (iii) Fused cluster of bizarre shape. firm consistency favouring bulge into retina rather than spread along Bruch's membrane. (iv) Fused cluster approximately 150 um in diameter. Contents have become dispersed except for a shell of amorphous material which remains around edge, hence the druse retains hard edges and nodular surface. Scale har represents $100 \mu \mathrm{m}$. Methylene blue and basic fushcin. $\times 320$. 


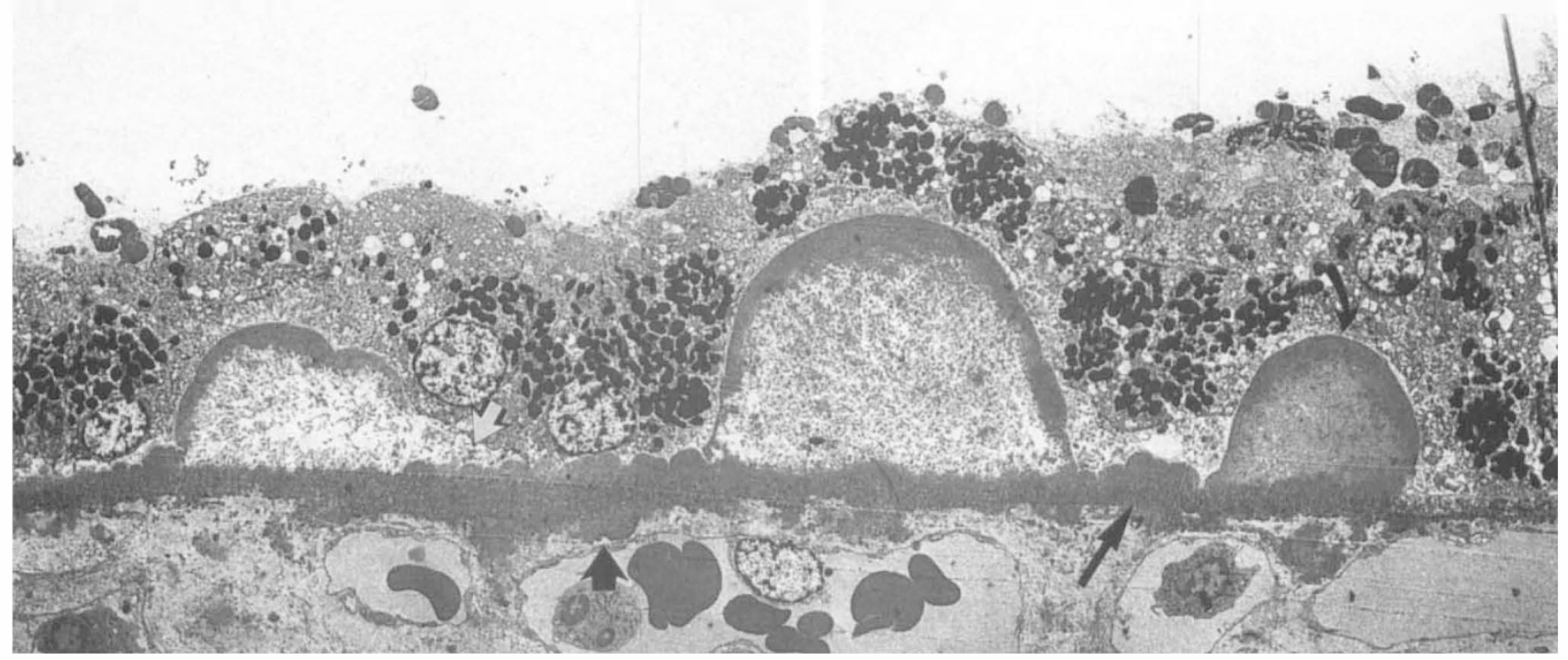

Fig. 3. Electron micrograph of discrete small hard drusen indicated in Fig. 2(i). The druse at the far right (curved arrow') demonstrates greater electron density around the margin than in the centre. Larger druse in the middle show's dispersion of contents except for a peripheral shell of amorphous material, outline of druse remaining sharp. Druse at left is similar but has lost the rim of amorphous material on one side (white arrowhead) and this edge is spreading ont on Bruch's membrane. Note the inner surface of Bruch's membrane is raised into a row of small rounded electron-dense elevations or microdrusen (black arrow) which also lie beneath the larger drusen. Similar extensions oc'ur on the choroidal side of membrane (back arrowhead). Despite the presence of numerous drusen there was no BLD or membranous debris in this eve. the patient being aged only 62 vears. $\times 2590$.

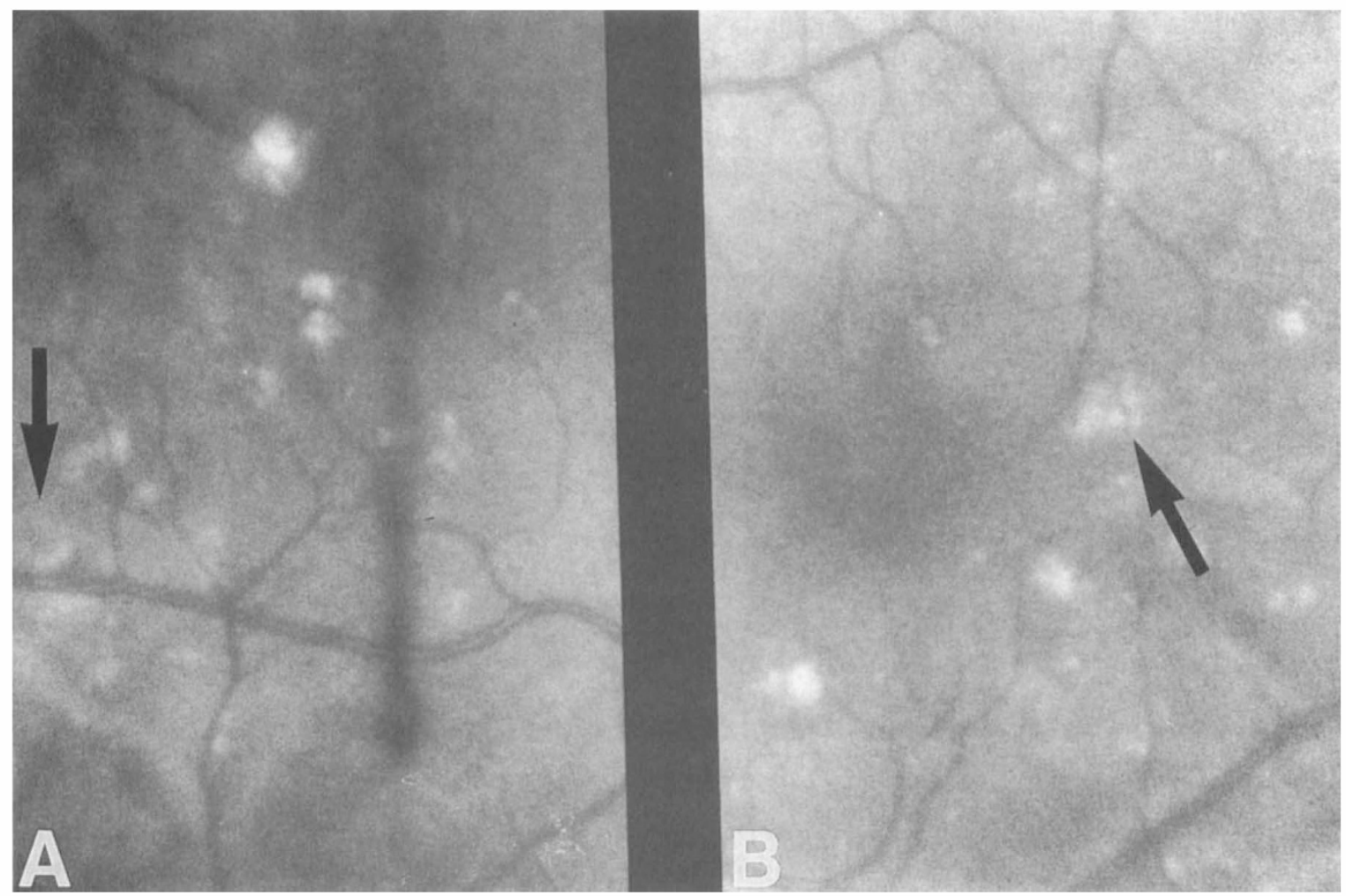

Fig. 4. Case 2. Right $(A)$ and left (B) fundus of a 74-year-old man with a moderate number of mainly small hard drusen showing a tendenc'v to cluster and fuse into larger deposits. Several drusen within the clusters had a whiter appearance and were overlain by small pigment clumps. but otherwise there was no significant pigment disturbance. Arron's point to groups of drusen from which sections are shonn in Figs. 5.6 and 7. Note the right forea lies above the tip of the fivation pointer. 


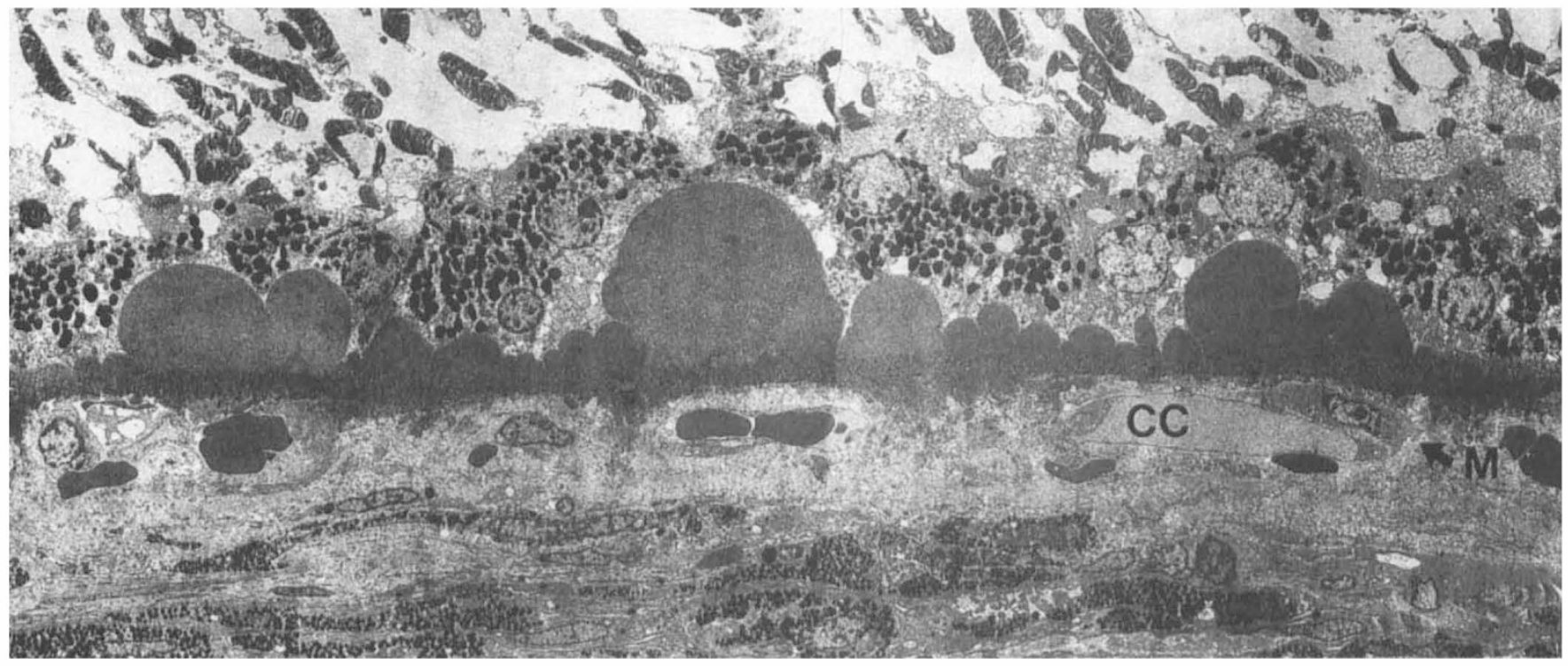

Fig. 5. Case 2. Electron micrograph showing a cluster of hard drusen from below and temporal to the right fovea, in the vicinity of the arrow in Fig. 4A. A contiguous series of small drusen lies on the inner surface of Bruch's membrane, the larger being less electrondense than the smaller. Only those drusen wider than tw' RPE cells would have been visible clinically. BLD is absent. As in the previous patient, macrophages $(M)$ related to outer surface of Bruch's membrane were sparse. CC. choriocapillaris. $\times 2100$.

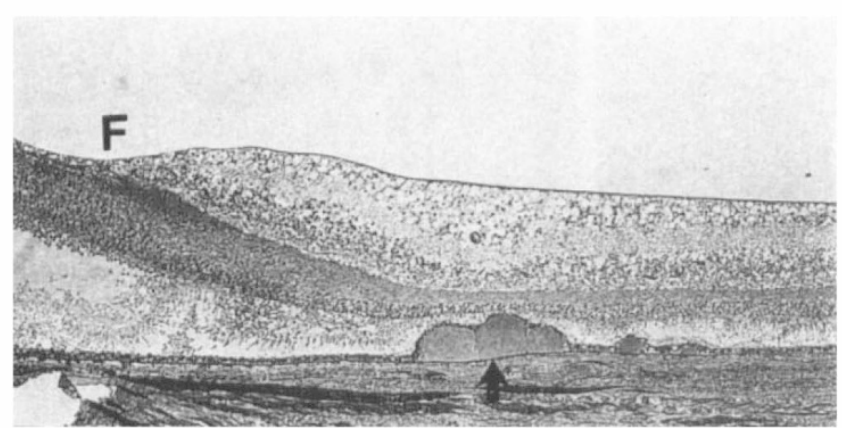

Fig. 6. Semithin section through the lateral part of the left forea $(F)$, showing fusion of three hard drusen into a larger deposit with sharply defined margins and lobulated surface (arrow). This cluster is $85 \mu \mathrm{m}$ in height or four times that of most drusen in case 1 , therefore being much more obvious clinically. The outer nuclear layer demonstrates a localised area of thinning over the drusen. Methylene blue and basic fuchsin, $\times 80$.

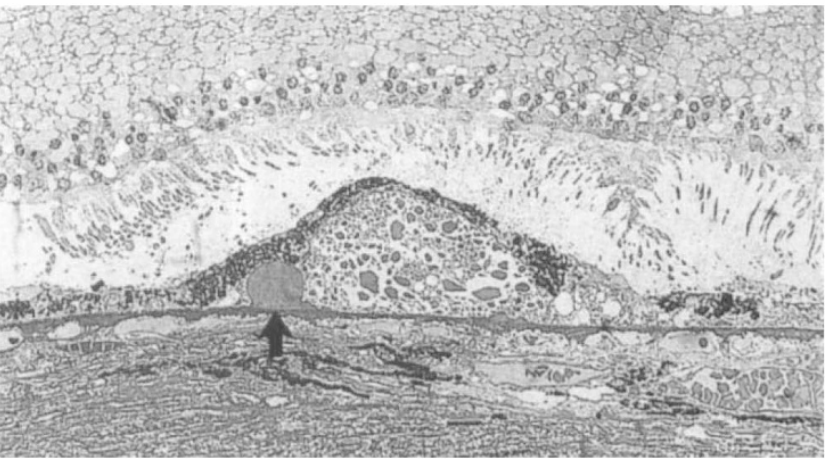

Fig. 7. Case 2, left eye. Semithin section in the vicinity of the arrow in Fig. 4B, showing a pair of fused drusen, contents remaining unmingled. Larger druse has spread out along Bruch's membiane and has coarsely granular structure due to breakdow'n into irregularly shaped fragments, the shape of which suggests they would dovetail together. The tendency of contents to fragment, even if a post-mortem change, is probably a function of the RPE. RPE over small hard druse at left (arrow') remains intact although swollen with lipofuscin granules, whereas RPE over broken-don'n druse seems about to disappear and there is fallout of overlying photoreceptors. Methylene blue and basic fuchsin, $\times 320$. 


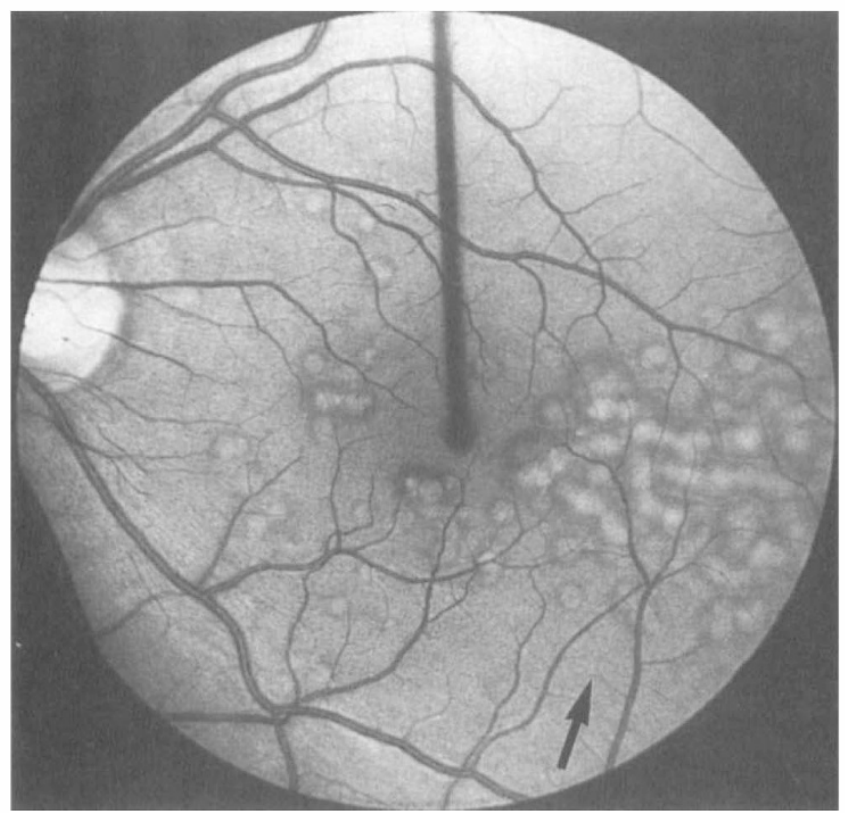

Fig. 8. Case 3. Red-fiee photograph of the left fundus of a 31 vear-old man with mumerous drusen about 200 $\mu \mathrm{m}$ in size. Many are surrounded by a reddish halo reflecting abruptly elevated margins. These deposits represent a cluster of small hard drusen which have fused and, despite their soft clinical appearance. are termed hard clusters. The arrow points to a barely visible cluster whach was traced orer the nevt 6 years (Fig. 9).
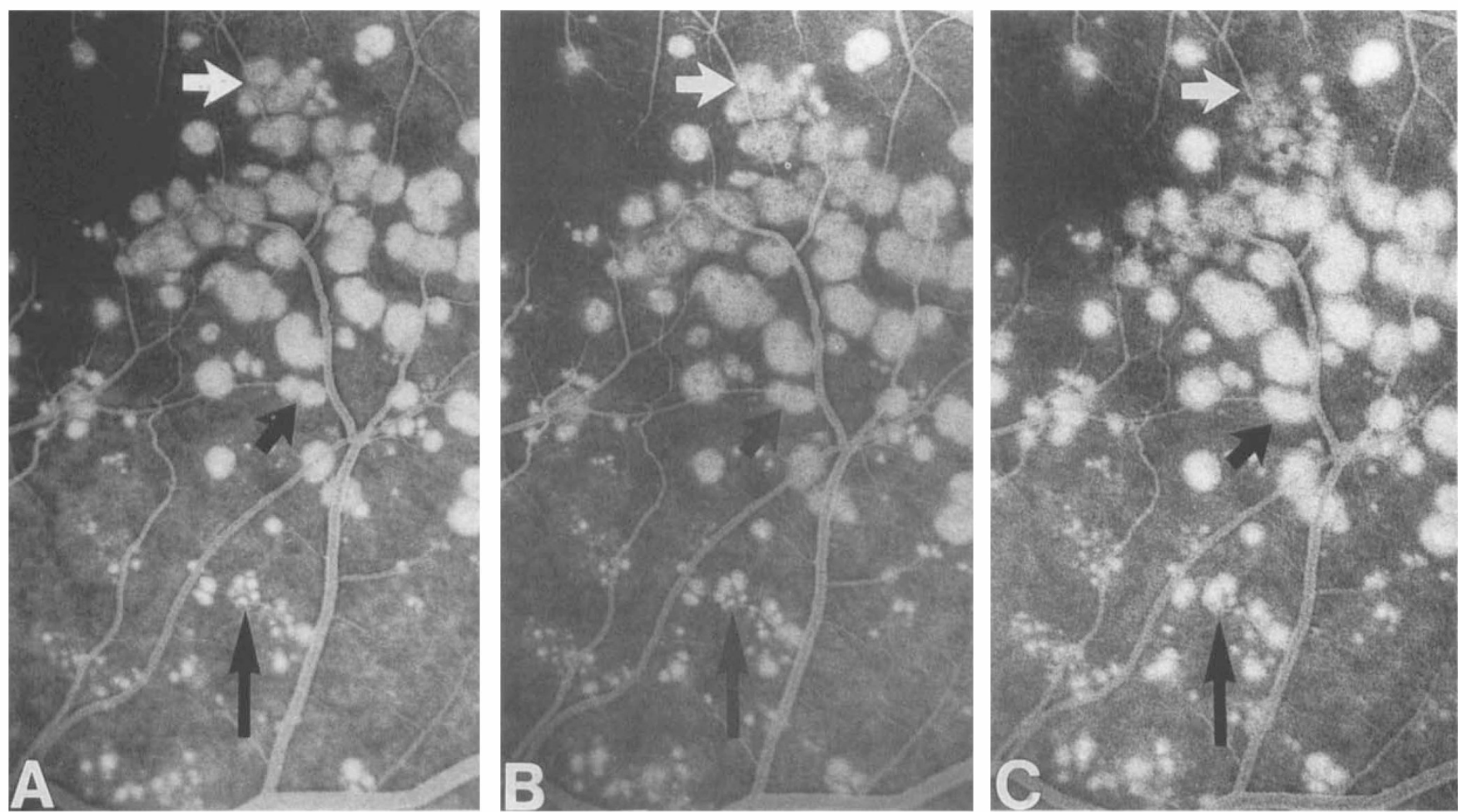

Fig. 9. Case 3. (A), (B) and (C) represent a sequence of fluorescein angiograms at age 31,33 and 37 vears, showing fusion of small hard drusen. The lower arrow points upwards to the ('luster show'n in Fig. 8, in which the small hard drusen are initially discrete, then enlarge and fuse. The centre arrow points to two larger drusen which also fuse. Fused clusters ultimately regress (white arrow' at top) to leave a focal patch of disturbed RPE. 

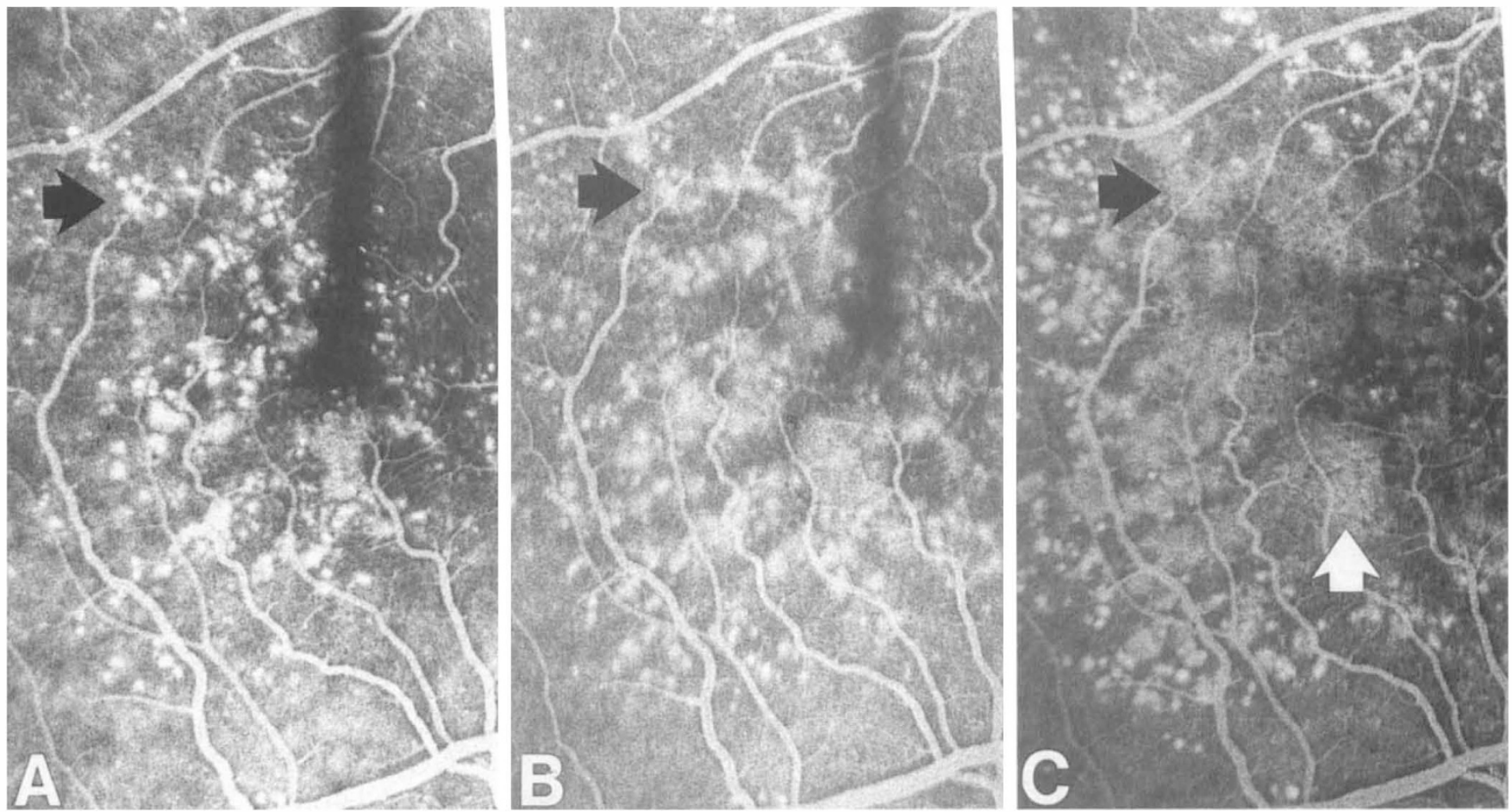

Fig. 10. Case 4. $(A),(B)$ and $(C)$ represent fluorescein angiograms of the right eve of man at age 55.58 and 63 years, showing evolution of a cluster of small hard drusen into larger soft drusen (black arrowhead). The small drusen are initially discrete (A), then become confluent but remain identifiable around the mar in of the cluster (B). In (C) the druse appears homogeneous, filling slowly and evenly on fluorescein angiography. This druse is shown again in Fig. II. The same evolution can be seen bv tracing the changes in drusenfrom the perifovea into the forea. Thus in (C) the drusen fur thest from the forcaremain discrete. Closer to the forea they form clusters in which the individual drusen are more difficult to distinguish. Those clusters at the margin of the forea have become homogeneous on fluorscein angiography and are beginning to regress with pronent stippling on the surface (white arrowhead).

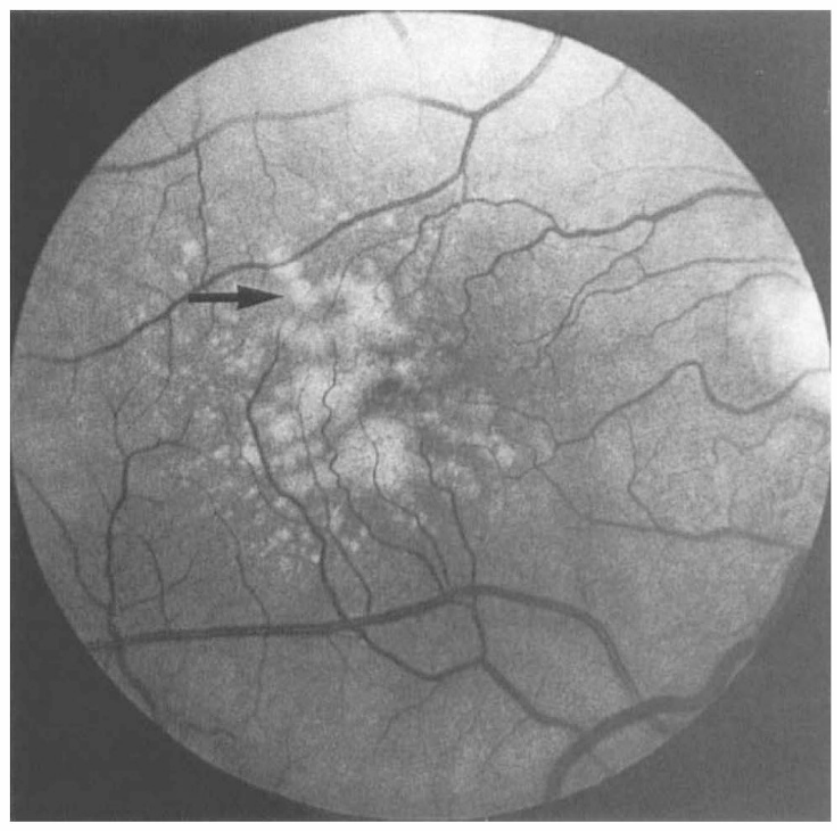

Fig. 11. Red-free photograph corresponding to Fig. I0C. showing large soft drusen. The arrow points to a drusé which was seen in Fig. 10 to evolve from a cluster of small hard drusen.

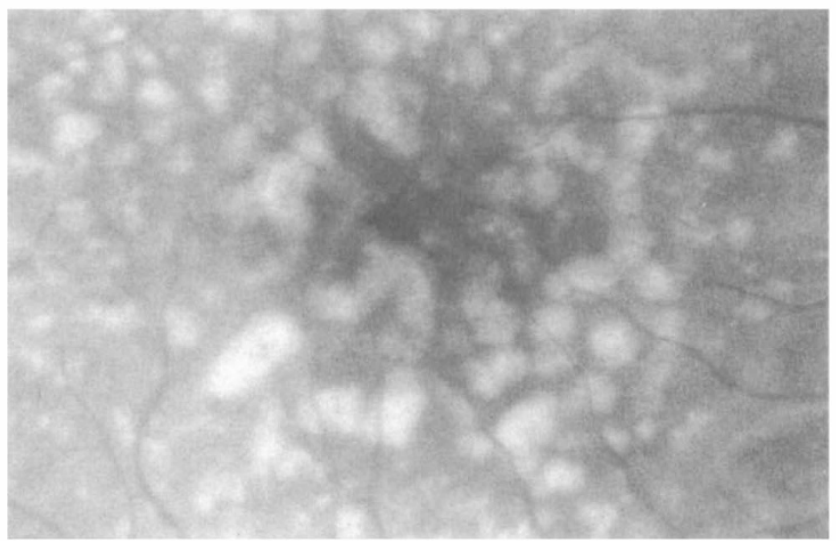

Fig. 12. Case 5. Right forea of a 72-year-old man with 6/9 part rision. showing mumerous soft drusen with ill-defined edges. These drusen appear to have formed firom clusters of small hard drusen. Confluence of these larger drusen in turn has resulted in sinuous deposits measuring up to $480 \mu \mathrm{m}$ and representing the distribution of the original drusen clusters. Shortly before death at age 75 vears vision in the right eye was $6 / 18$ and some of the drusen had a whiter appearance and sharper edges indicating earlir regression. 


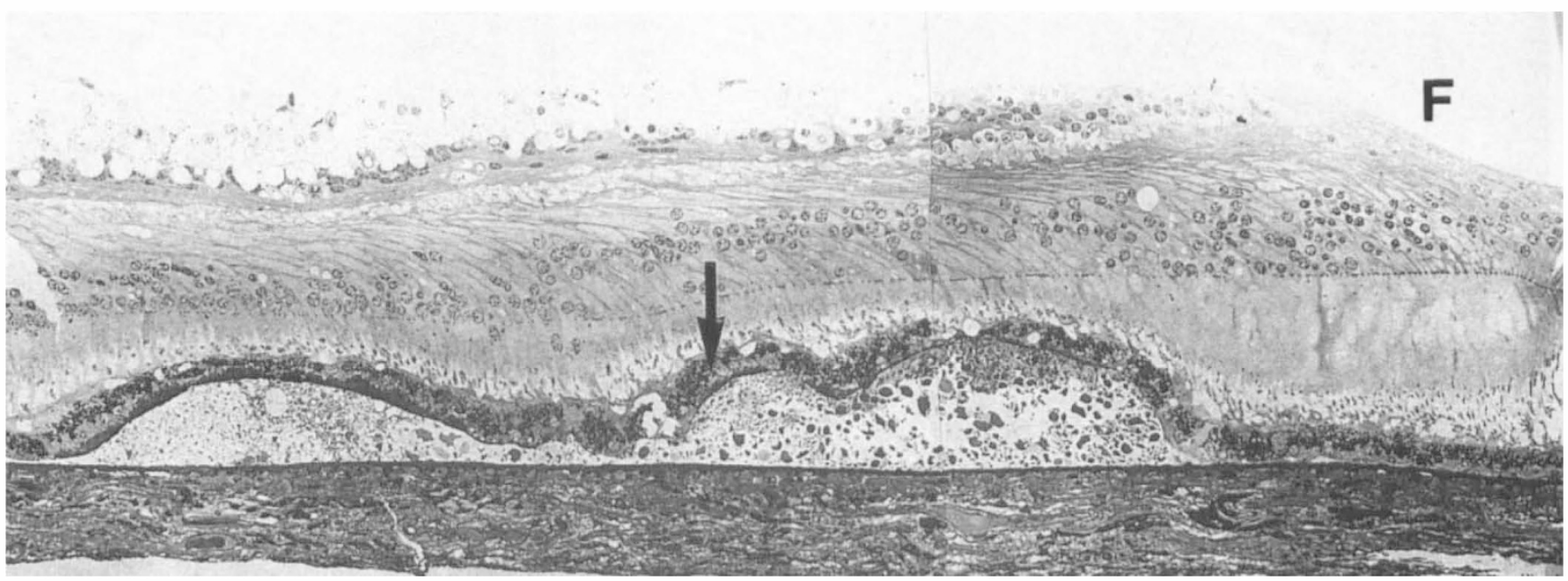

Fig. 13. Case 5. Semithin plastic section through the edge of the fove $(F)$ of the eye illustrated in Fig. 12, showing confluent soft drusen. Drusen contain granular material apparently derived from the breakdown of small hard drusen, several of which were still present nearby. Note that as contents break down, drusen tend to lose both the sharp margins and the nodular surface elevations of fused hard clusters. Over the drusen the RPE is irregular, the photoreceptors are stunted and there is loss of photoreceptor nuclei. The arrow points to the area magnified in Fig. 14. Methylene blue and basic fuchsin, $\times 205$.

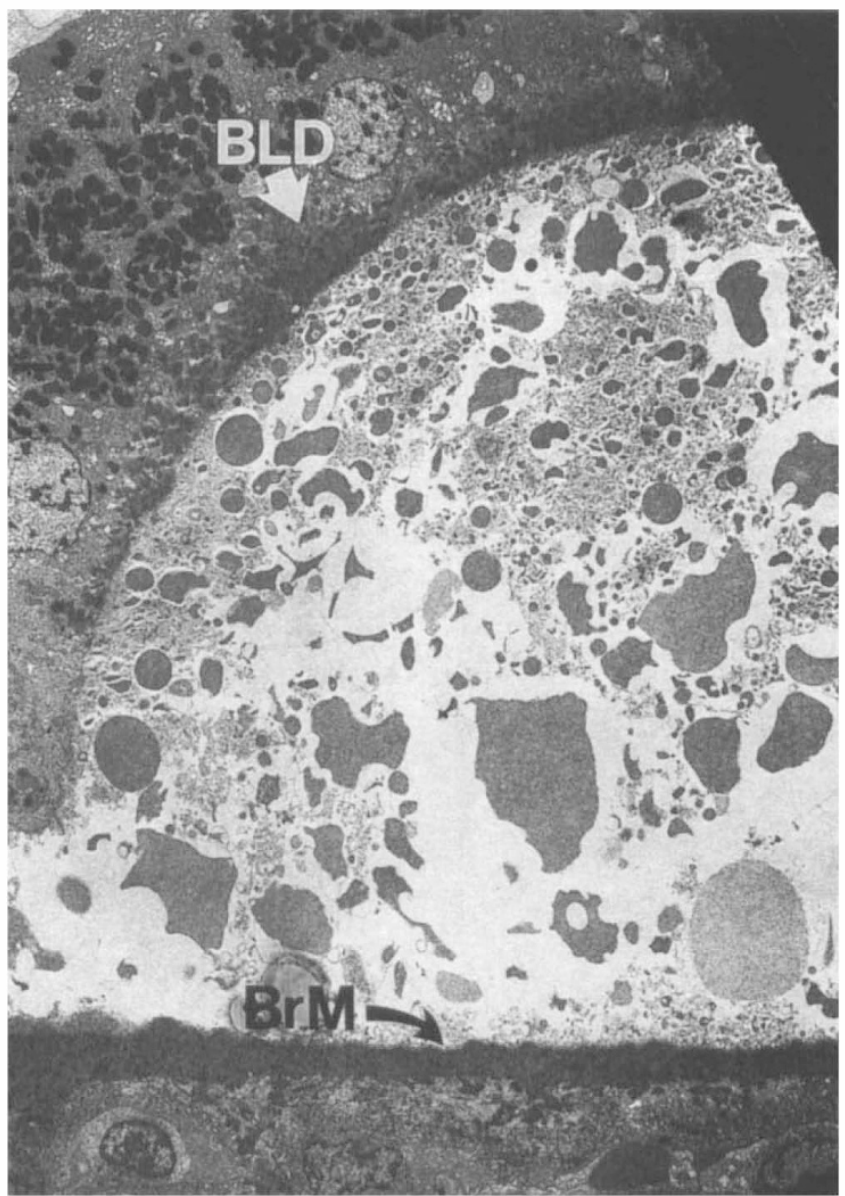

Fig. 14. Electron micrograph of the area indicated in Fig. 13. Coarsely granular appearance of drusen at low magnification is due to globules of amorphous material, some of which are round, others of more bizare shape. Material between globules has been lost in part but that which remains in the apical part of the druse comprises smaller amorphous particles, vesicles and membrane fragments. A continuous layer of banded BLD was present. BrM, Bruch's membrane. $\times 2480$. 

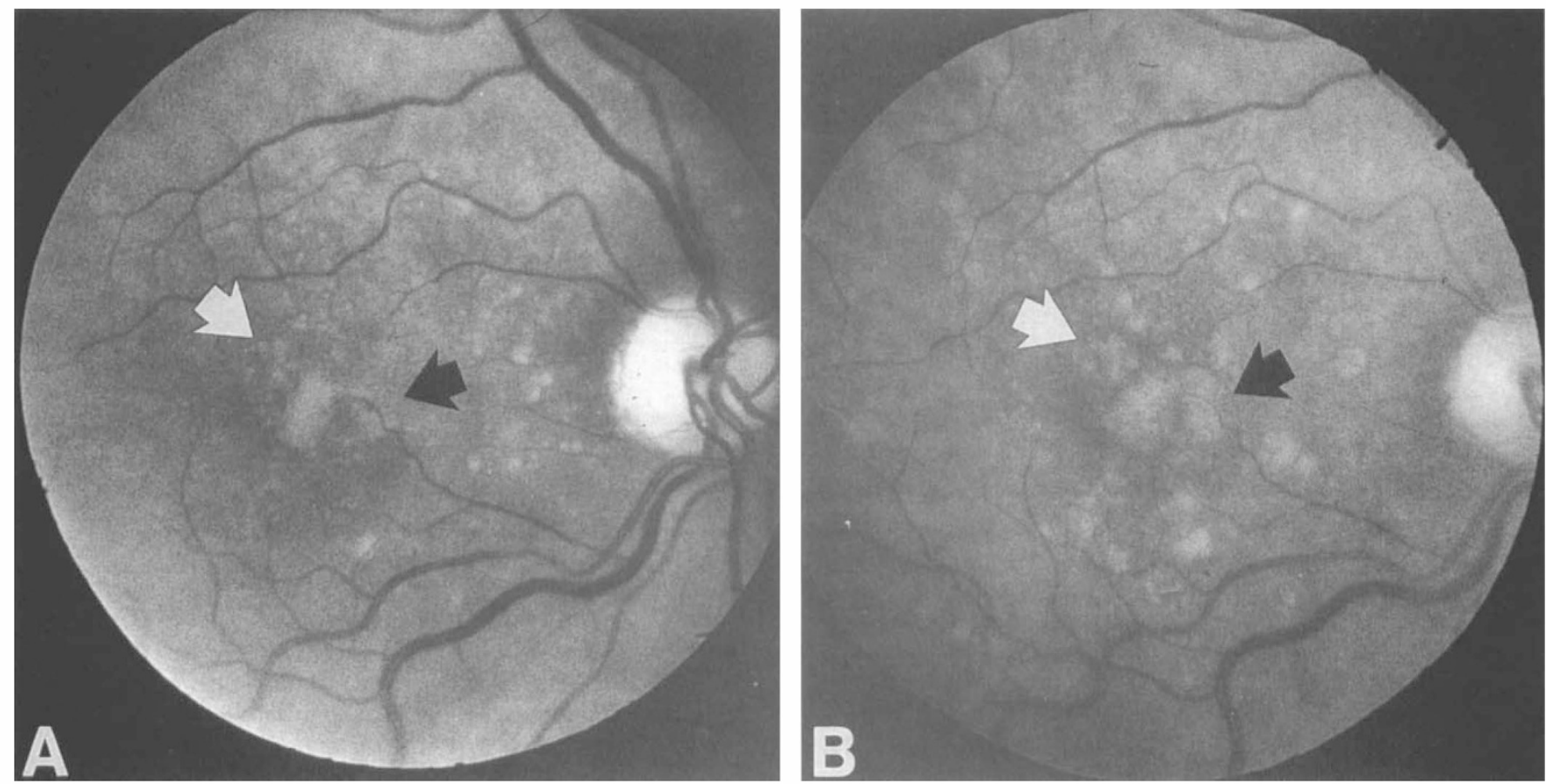

Fig. 15. Case 6. Right eve of a woman at age 78 years (A) and \&2 years (B), showing formation of soft cluster-derived drusen (white

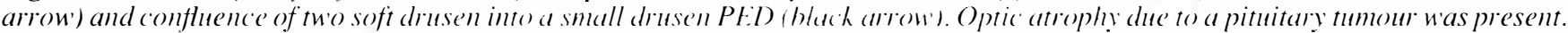

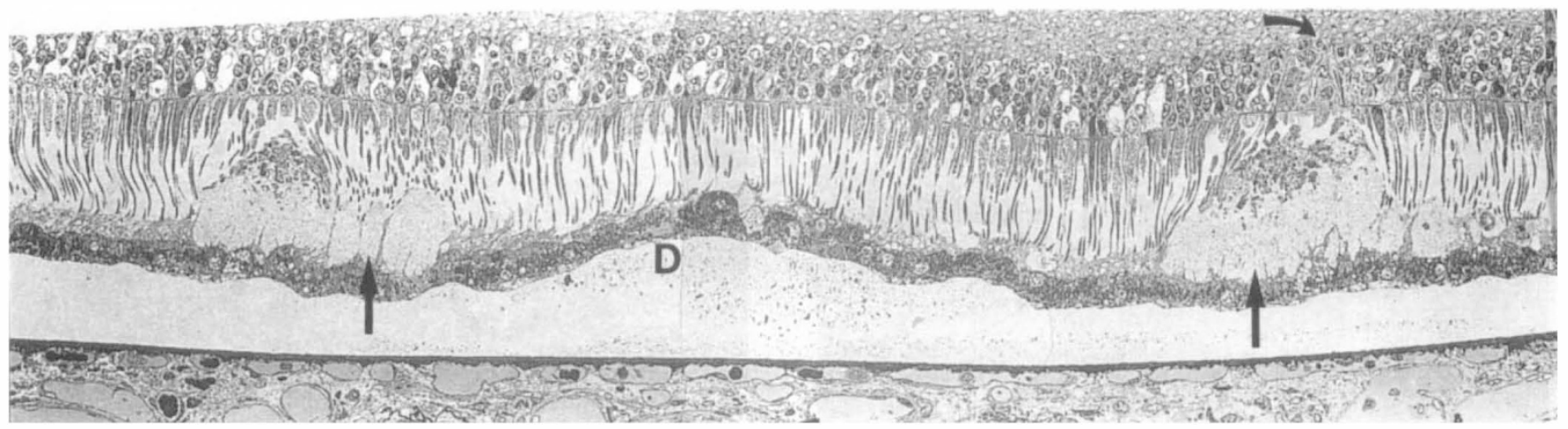

Fig. 16. Case 6. Semithin plastic section cut vertically through the smaller, more nasal of the two soft drusen indicated by the black arrow in Fig. 15, showing changes at basal and apical surface's of RPE. Separation of RPE from Bruch's membrane is probably artefactual, but the scalloped basal surface of the RPE suggests prior presence of a serie's of soft drusen. the largest shown at D. Contents are partly lost but appear to have been widespread and comprise finch granular muterial similar to that in the previous patient (Fig. 14); the particles of amorphous material were of smaller size. Overlving the largest druse (D) the photoreceptors appear fewer. but the most pronounced changes in the laver are seen on either side of the main druse as collections of mainly outer segment material (arrows), separated by broad apical extensions of the RPE. The photoreceptors become increasingly fragmented as they are traced into these mounds, the remaining inner segments appear blunted and widened and the outer nuclear laver is slightly reduced in thickness (curved arrow). Methylene blue and basic fuchsin, $\times 32($ ). 


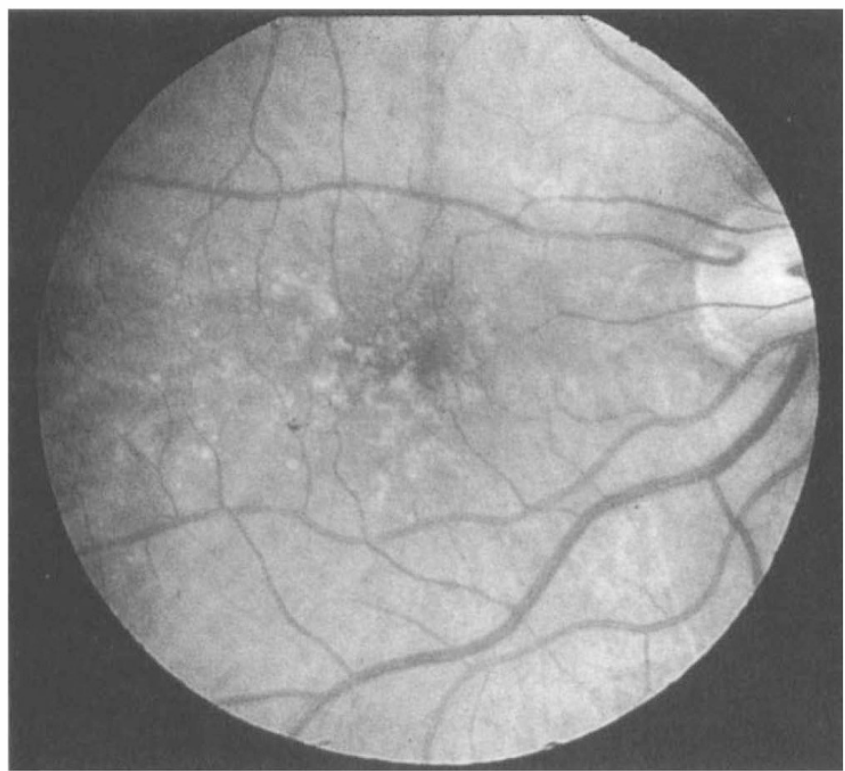

Fig. 17. Case 7. Right fundus of a 71 -year-old man showing both small hard drusen and shallow soft drusen of irregular shape, mostly less than $250 \mu \mathrm{m}$ in size. Similar drusen were present in the left eye and vision was 6/24 in each eve, attributed partly to a homonymous hemianopia. The right eye developed a haemorrhagic disciform lesion shortly before death at age 75 vears, but littlechange was observed in the left fundus. The morphology of the drusen in the left eye is illustrated in Fig. 18-21.

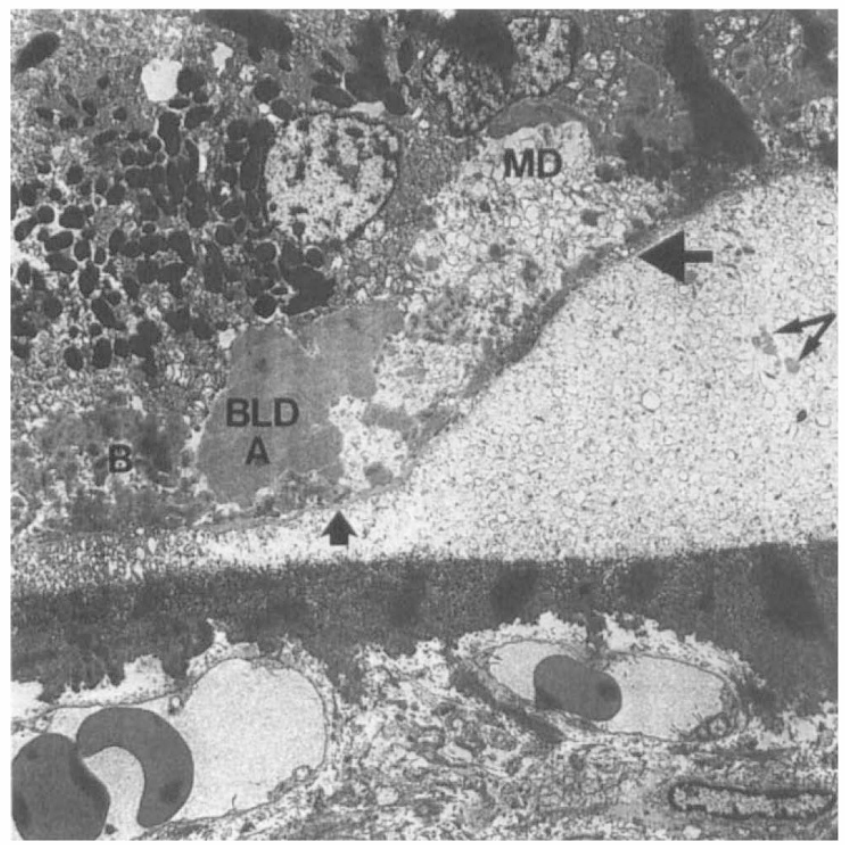

Fig. 19. Electron micrograph of the area indicated in Fig. 18. Soft druse is made up of coiled lipidmembranes lying external to the basement membrane of the RPE (arrowhead at left). Most coils appear empty; a few' contain amorphous material (double arow). Similar membranous debris is observed internal to the basement membrane (MD) between clumps of $B L D$ and appears to pass through the basement membrane into the druse (horizontal arow'). These membranous drusen are found onlv after $A M D$ has commenced. BLD comprised amorphous $(A)$ and banded $(B)$ material. $\times 3880$.

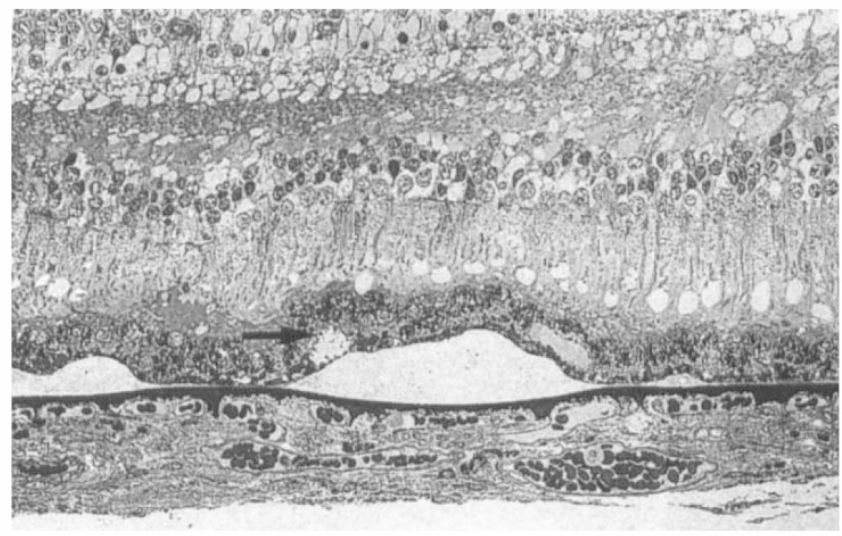

Fig. 18. Semithin section from left eye of the patient illustrated in Fig. 17, showing druse $200 \mu \mathrm{m}$ wide. These drusen represent focal accentuations of a continuous layer of debris and have sloping margins. It is into this plane that choroidal new'vessels grow and a neovascular membrane was present nearby (Fig. 20). Drusen appear empty or very finely granular at this magnification. The arrow points to a small mound of similar structure, lying above the druse. Higher magnification is show'n in Fig. 19. Methylene blue and basic fuchsin, $\times 320$.

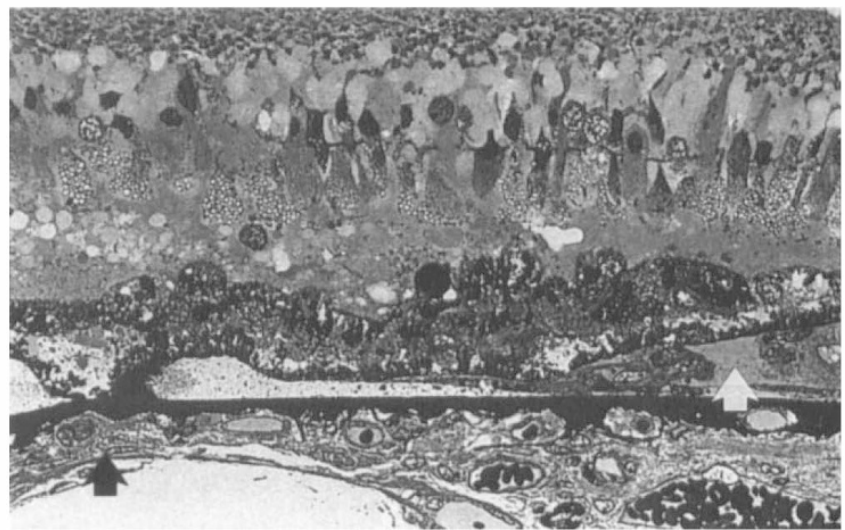

Fig. 20. Semithin section from eve illustrated in Figs. 17-19, showing a neovascular membrane at the right (white arrow' head), spreading in the plane opened by membranous debris. At the left a group of subclinical small hard drusen are breaking down and macrophage-type cells are applied to the outer surface of Bruch's membrane here (black arrowhead). Note that the $B L D$ and RPE remain anchored at the site of hard drusen, but are separated from Bruch's membrane on either side of membranous debris. This ma permit a retinal stimulus to evoke the maximum cellular response in the choroid directly beneath these drusen. Methylene blue and basic fuchsin, $\times 512$. 


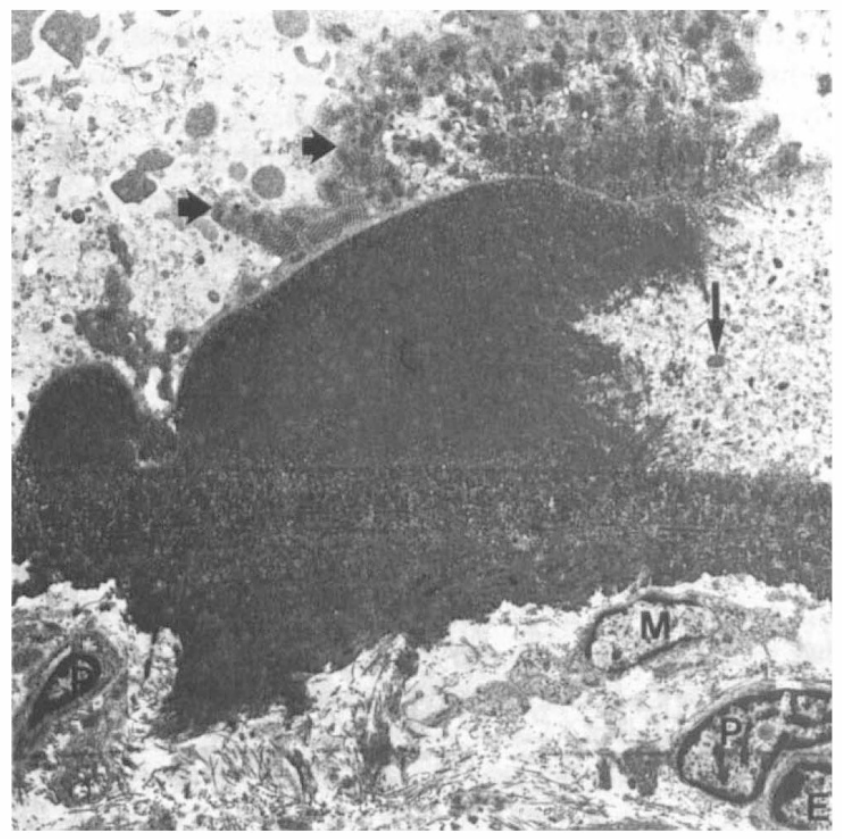

Fig. 21. Electron micrograph of the area of hard drusen breakdown indicated in Fig. 20, show'ing formation of mixed drusen. Amorphous material is fragmenting into small particles (vertical arrow') and is becoming incorporated into soft membranous drusen. Banded BLD orerlies drusen (horizontal arrow's). Macrophage-type cells $(M)$ are apposed to Bruch's membrane beneath hard drusen. Other cells present appear to be pericytes $(P)$ and endothelial cells $(E) . \times 6270$.

angiography their margins were clearly defined. Over the ensuing 6 years the formation of these larger drusen could be shown to result from the fusion of small hard drusen arranged in clusters (Fig. 9). These drusen were termed hard clusters.

\section{Case 4. Soft Cluster-Derived Drusen (Soft Clusters)}

The patient was a 55-year-old man showing varying stages of drusen breakdown over the next 8 years, vision remaining 6/6. Small hard drusen within clusters were initially discrete (Fig. 10A) and for a time remained identifiable on fluorescein angiography, mostly around the margin of the clusters (Fig. 10B). With further breakdown the clusters appeared homogeneous in red-free light and filled slowly and evenly on fluorescein angiography, no longer showing evidence of their derivation from hard drusen (Fig. 10C). The clusters had developed into large soft drusen with indistinct edges (Fig. 11). The same transition from clusters of small hard drusen to larger soft drusen could be seen also at any one time (Fig. 10C). The drusen furthest from the fovea remained discrete, but closer to the fovea they formed clusters in which the individual drusen were more difficult to distinguish, due to fusion and partial breakdown. Those clusters at the margin of the fovea had become completely homogeneous on fluorescein angiography.

\section{Case 5. Confluent Soft Drusen Derived from Clusters}

The patient was a 72-year-old man suffering from cerebral arteriosclerosis and chronic obstructive airway disease. His fundi demonstrated soft drusen apparently derived originally from broken-down drusen clusters. Confluence of these soft clusters in turn produced larger deposits of crescentic or sinuous shape (Fig. 12). Histopathologically the BLD was widespread under the macula. The drusen differed from the clusters of fused hard drusen in so far as they no longer had a cortex of amorphous material, losing the nodular appearance and instead displaying sloping edges (Fig. 13). They had a coarsely granular structure due to the amorphous material having broken up into globules. The drusen contents between the globules, which were better preserved in the apical regions, contained membrane fragments and other debris (Fig. 14).

\section{Case 6. Drusen Pigment Epithelial Detachment Formed by Confluence of Soft Clusters}

The patient was a 78-year-old woman who had undergone hypophysectomy for a pituitary tumour. Soft drusen derived from hard clusters were present and formed a small drusen pigment epithelial detachment (PED) over a 4 -year period of observation (Fig. 15). Vision fell from $6 / 9$ to $6 / 24$ over this time but optic atrophy and a bitemporal hemianopia were present. Fluorescein angiography demonstrated slow filling of the soft drusen. The drusen proved to contain granular material (Fig. 16) similar to that in case 5, but the globules of amorphous material were smaller and more membrane fragments were present. The overlying outer segments showed moderate distortion and separation, but the most pronounced indication of impaired phagocytosis occurred as focal collections of mainly outer segment debris, although not located directly over drusen. In these areas the photoreceptors became increasingly fragmented as they were traced into the mounds of debris, the remaining inner segments appeared blunted and the outer nuclear layer demonstrated slight fallout. These accumulations were initially discrete, being separated by broad apical extensions of the RPE which appeared ultimately to give way, allowing larger mounds to form up to ten RPE cells wide.

\section{Case 7. Soft Membranous Drusen, Neovascular Membrane}

The patient was a 71 -year-old man who was normotensive but suffered from hemiparesis and homonymous hemianopia. He became progressively demented and died at age 75 years. Both fundi showed soft drusen of irregular shape, shallower and less yellow in appearance than in the previous patient and confined to the inner macula (Fig. 17). Small hard drusen were scattered among the soft drusen. A fluorescein angiogram could not be obtained.

Diffuse changes of AMD were present in the form of a continuous layer of BLD interspersed with collections of membranous debris lying internal to the RPE basement membrane (Figs. 18, 19). The drusen consisted of larger accumulations of the same membranous material lying external to the basement membrane and continuity 
appeared to occur through the basement membrane (Fig. 19). Most of the membrane coils appeared empty; others contained small amounts of amorphous material indistinguishable from that found in cluster-derived drusen. Where small hard drusen were in contact with the membranous drusen the amorphous contents appeared to be disintegrating into small particles (Figs. 20, 21 ).

The membranous drusen caused widespread separation of the RPE basement membrane from Bruch's membrane and a neovascular membrane was found spreading in this cleavage plane (Fig. 20). However, the basement membrane was more firmly attached to hard drusen so that at these sites the RPE remained anchored to Bruch's membrane. Macrophage-type cells noted in relation to the outer surface of Bruch's membrane were most numerous beneath these hard drusen (Figs. 20, 21 ) and were of ten related to thinned segments of the membrane.

\section{Types of Drusen}

On the basis of fluorescein angiography and pathological examination drusen could be divided into four main groups: (1) small hard drusen; (2) drusen showing evidence of their derivation from clusters of small hard drusen, which includes drusen of soft appearance and encompasses most larger drusen; (3) soft membranous drusen which develop only after AMD has commenced and do not become manifest before the seventh decade; and (4) regressing drusen. This terminology is presented in Table I and related to other definitions in use. Some of the terms are clinical, others morphological and yet others combine both characteristics.

\section{DISCUSSION}

\section{Small Hard Drusen}

Small hard drusen may occur at a young age and continue to be formed during life, becoming almost universal. ${ }^{4}$ The formation of hard drusen has features in common with the ageing of Bruch's membrane, since on electron microscopy both may contain membrane-bound bodies in varying stages of disruption ${ }^{20}$ while on light microscopy both have similar staining properties and appear hyalinised. ${ }^{10.12-15}$ Focal densifications of Bruch's membrane, termed microdrusen, may precede the formation of the overlying small hard drusen. When small hard drusen grow larger than about $63 \mu \mathrm{m}$ in size (half the width of a major retinal vein at the disc edge) the amorphous contents become less compact, referred to herein as dispersion. This commences in the lower part of the drusen, leaving a rim of amorphous material such that their shape remains unaltered. Single hard drusen rarely exceed $125 \mu \mathrm{m}$ in size and further enlargement is the result of fusion of several drusen.

\section{Drusen Derived from Clusters of Small Hard Drusen}

(a) Hard clusters: clustering and fusion. The natural disposition of small hard drusen to occur in clusters is a long- established observation. Oeller ${ }^{21}$ in 1899 illustrated the tendency of "verrucae laminae vitreae . . to agglomerate, thereby forming many peculiar and dumb-bell shaped groups'. Where this is not evident on fundoscopy it may be brought out by fluorescein angiography, but it is most apparent on pathological examination as many of the drusen are too small to be seen clinically. Initially the small hard drusen in a cluster are discrete or touching (subconfluent ${ }^{17}$ ), but if closely packed together they fuse into a single larger deposit. As the contents become dispersed the individual drusen become difficult to distinguish even on fluorescein angiography, but as long as a rim of amorphous material remains the deposit will demonstrate a series of nodular surface elevations and well-defined margins (Fig. 2-iv). They have therefore been termed large hard drusen, ${ }^{12}$ but since they have an obvious thickness they have also been referred to as soft distinct drusen. ${ }^{1.5}$ In this discussion they are termed 'hard clusters - drusen discrete or fused', according to whether the individual small hard drusen within the cluster can be distinguished. Fused hard clusters occur in middle age and the prognosis is generally good unless a deposit threatens fixation, the drusen slowly regressing over many years to leave a focal patch of thinned or atrophic RPE.

(b) Soft cluster-derived drusen (soft clusters): partial or complete breakdow'n of small hard drusen. Softening of the margins of hard drusen occurs when the base spreads out along Bruch's membrane. This is associated with breakdown of the amorphous contents into globules, giving the drusen a coarsely granular structure. This soft-

Table I. Comparative terminology of drusen

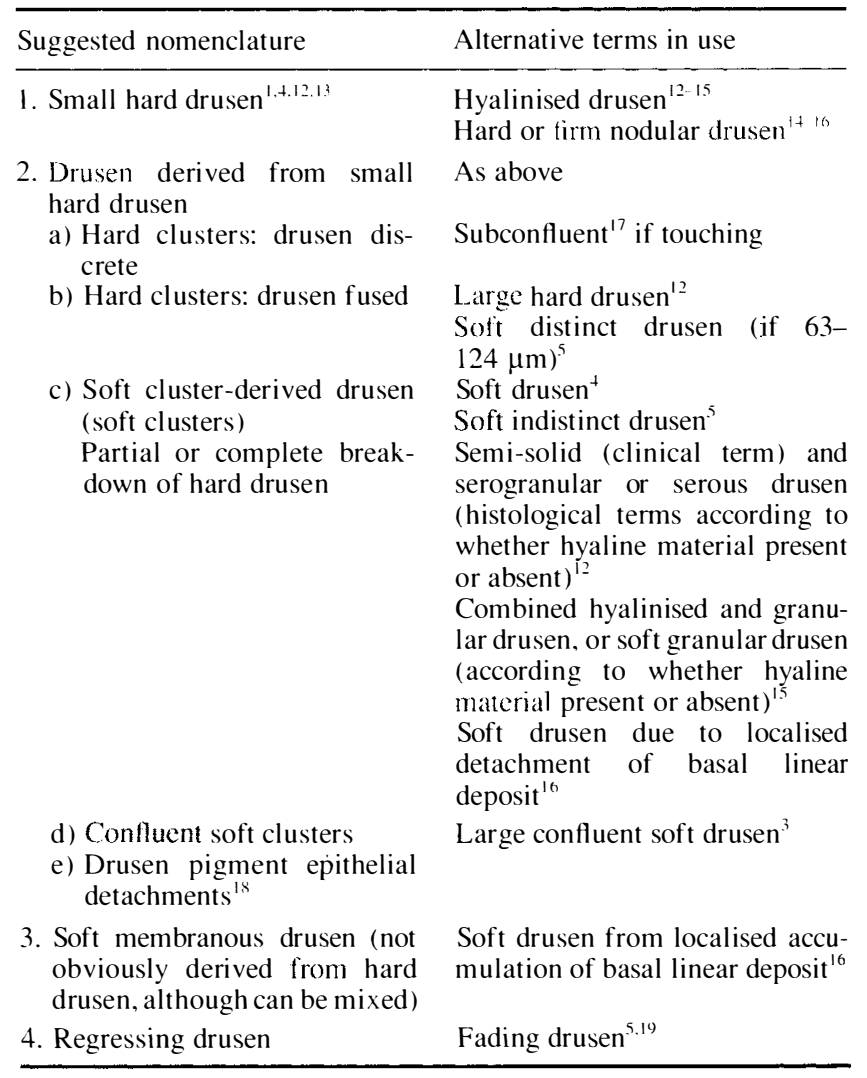


ening process may first affect the older drusen in the centre of a cluster, with small drusen remaining identifiable around the margin. On fluorescein angiography the centre of such a cluster stains less brightly than the hard drusen material around the margin (Fig. 10B) and this is believed to be due to their content of neutral fat which would inhibit the entry of water-soluble dyes..$^{22}$ However, the histochemical processes occurring during softening are unknown. Although lipid accumulation in Bruch's membrane increases with age, the total amount of lipid and the ratio of neutral fat to phospholipid varies widely ${ }^{23}$ and no correlation has been found between histochemistry and the ultrastructural appearances, ${ }^{24}$ probably because of the removal of neutral lipid during processing for electron microscopy.

Alternative clinical names suggested for these partially broken down clusters are semisolid drusen ${ }^{12}$ and soft indistinct drusen, ${ }^{1.5}$ while morphological terms that have been used are serogranular ${ }^{12}$ or combined hyalinised and granular drusen. ${ }^{15}$ Later the drusen may no longer show any clinical evidence of their derivation from clusters of hard drusen, appearing homogeneous in red-free light (Fig. 11) and staining uniformly on fluorescein angiography (Fig. 10C). Histologically, drusen in which the globules have broken down further to a very finely granular material have been termed soft serous drusen ${ }^{12}$ or soft granular drusen. ${ }^{15}$

Soft clusters have a yellow appearance with indistinct edges and are rare before the age of 55 years. The same evolution from clusters of small hard drusen into larger soft drusen may be seen at any one time when drusen are traced from the perifovea towards the fovea, the breakdown of the clusters being more advanced around the perimeter of the fovea (Fig. 10C). This is in keeping with the fact that AMD is of ten most advanced in this band," since this is where the consideration of xanthophyll is tapering off..$^{25}$ The breakdown of clusters may therefore precede the development of corresponding patches of drusen-related atrophy. Calcified particles may be found in these drusen and they appear to be the forerunner of regressing drusen.

(c) Confluent soft clusters/drusen pigment epithelial detachments. The confluence of soft drusen derived from drusen clusters produces larger crescentic or sinuous shapes (Fig. 12), apparently reflecting the distribution of the original clusters of small hard drusen. Large confluent sof t drusen are termed drusen pigment epithelial detachments. ${ }^{18}$ These sof t drusen probably enlarge by the imbibition of fluid which the RPE may have been unable to pump out of the retina if the lipid nature of the membranous debris creates a hydrophobic barrier in Bruch's membrane. ${ }^{26}$ It is also probable that fluid first enters drusen at an earlier stage because the shape of the separated globules or fragments of ten suggests they would fit together like a jigsaw puzzle and the basement membrane is sometimes found to be folded into the drusen. The larger and more fluid the soft drusen have become, the finer the par- ticles into which the original amorphous hard drusen material is found to have disintegrated and the more rapidly the drusen develop and fade, more often leading to geographic atrophy than choroidal neovascularisation.

\section{Soft Membranous Drusen}

These are derived from debris specific for AMD. The tightly packed membrane coils that first collect between the RPE and its basement membrane later appear also on the external aspect of the basement membrane. Here they may build up into soft drusen which, being focal accenuations of a continuous layer of debris, have indistinct margins and readily become confluent. While membrane coils were the predominant constituent of these drusen, some of the coils also contained amorphous material indistinguishable from that in granular drusen. Soft membranous drusen occur after age 65 years and, on fundoscopy, are smaller and less conspicuous than the larger yellow drusen derived from clusters and are confined to the inner macula. Other distinguishing characteristics have not been identified, all soft drusen fluorescing less brightly and later in the angiogram than hard drusen. Small hard drusen usually coexist with these soft membranous drusen but do not seem to be a prerequisite for their development. However, hard drusen may become incorporated into membranous drusen, resulting in mixed types (Fig. 20).

\section{Regressing Drusen}

The photoreceptors are dependent upon the ability of the RPE to recycle materials essential for their renewal and to dispose of the residue. Since drusen probably reflect in part a failure of degradative enzymes, ${ }^{24}$ some disturbance of photoreceptor function would be expected to develop over drusen. However, retinal sensitivity under darkadapted conditions appears to be the same over drusen and non-drusen areas. ${ }^{27}$ Moreover, although the accumulation of outer segment material at the apical surface of the RPE suggest phagocytosis is impaired ${ }^{28}$ (Fig. 16), these changes are not necessarily more pronounced over drusen and similar collections of outer segment debris have been noted during the evolution of geographic atrophy of the RPE. " Therefore, despite the physical intrusion of large drusen into the photoreceptors resulting in distortion and fallout of these cells, the functional capacity of the RPE remains the main factor influencing both the integrity of the photoreceptors over drusen and the lifecycle of the drusen themselves.

All types of drusen therefore start to regress once the overlying RPE fails. Clinically regressing drusen develop a whiter and harder appearance, with pigment stippling over the surface. Occasionally soft drusen fade with little trace other than a patch of attentuated RPE. More usually the drusen shrink slowly, developing irregular margins and foci of calcification before disappearing to leave a focal patch of atrophy. Most cases of geographic atrophy of the RPE evolve in relation to regressing drusen. ${ }^{11.19}$

\section{Clinical Distinction of Hard Versus Soft}

It is apparent from case 1 that the contents of even small 
drusen may vary in consistency, dispersing centrally while the margins remain firm, so that the drusen retain their shape. That the dispersed contents are nevertheless soft is indicated by the base of the druse spreading out where the firmer shell has disappeared (Fig. 3). Similarly, only the centre of fused clusters may soften initially. Margins and contents can therefore give conflicting clinical impressions about drusen consistency, but since the designation as soft implies a predisposition to spread out on Bruch's membrane and become confluent, in this discussion drusen that retain well-defined margins are regarded as hard. A distinction based on size alone is unsatisfactory, especially since regressing drusen can have the hardest appearance of all drusen types and yet be quite large.

\section{Location of Debris in Relation to Basement Membrane of RPE}

The BLD was originally termed the basal linear deposit, ${ }^{10}$ but the name was later changed to basal laminar deposit. ${ }^{12}$ This deposit has not always been clearly distinguished from the membranous debris lying external to the basement membrane which also forms a diffuse layer, but which may build up focally into drusen. As a consequence these diffuse deposits have also been referred to as diffuse drusen or diffuse thickening of the inner aspect of Bruch's membrane. ${ }^{26,29}$ Recently Green and Enger ${ }^{16}$ have addressed this confusing subject and used the term basal laminar deposit for the material internal to the basement membrane, while retaining the term basal linear deposit for the diffuse deposits located on the external aspect. They therefore distinguished three types of soft drusen which might be correlated with the present study as follows: (i) Localised detachment of the basal laminar deposit, which would represent typical drusen over which BLD has formed and so occur in established AMD. (ii) Localised detachment of the basal linear deposit. This type could correspond to soft clusters, partially broken down, in which membrane fragments remain in the apical region and so may appear as a separate layer consisting predominantly of vesicular and granular material as illustrated in Fig. 14. (iii) Localised accumulation of basal linear deposits, which appears to correspond to soft membranous drusen.

\section{Association Between BLD and Choroidal Neovascularisation}

In an earlier light microscopical study of subretinal new vessels in post-mortem eyes, ${ }^{30}$ the vessels appeared to be invading the BLD. However, it was not fully appreciated that these were inactive vessels and later an association with soft drusen was confirmed. ${ }^{6}$ The fact that there is a strong positive association between the BLD and choroidal neovascularisation ${ }^{16}$ is because the BLD reflects degeneration of the RPE and the formation of membranous debris, but it does not itself appear to stimulate new vessel ingrowth. The BLD in its amorphous form persists in areas of geographic atrophy long after the RPE and membranous debris have disappeared and the risk of neo- vascularisation has declined. The BLD also determines the distribution of soft membranous drusen, the membrane coils first being noted between clumps of banded BLD material before building up on the external surf ace of the RPE basement membrane. Soft membranous drusen are therefore limited to the inner macular where the BLD is most developed.

\section{Association Between Drusen and Choroidal Neovascularisation}

The two pathways of soft drusen formation appear to have differing implications. The soft cluster-derived granular drusen predispose to avascular PEDs ${ }^{31}$ and in pathological specimens are more of ten found around areas of atrophy, whereas the soft membranous drusen are commonly found in the vicinity of neovascular membranes. The role of membranous debris may in part be to open a cleavage plane, but it may also contribute to the generation of an ischaemic stimulus in the outer retina as a result of the widespread separation of the RPE and photoreceptors from their choroidal blood supply.

Macrophages may play a role in the initial phases of choroidal neovascularisation. Activated macrophages are known to secrete growth factors stimulating vascular proliferation ${ }^{32}$ and, since they have been observed in relation to thinned segments of Bruch's membrane, ${ }^{33}$ they may be responsible for establishing a passage for the early new vessels. Macrophages and giant cells related to the outer surface of Bruch's membrane are found in increasing numbers once membranous debris accumulates, but paradoxically they then occur preferentially beneath hard drusen. This does not appear to be a response to the hard drusen material alone because the cells are infrequent before membranous debris appears, even when hard drusen are very numerous as in case 1 . One possible explanation is that, once widespread separation of the outer retina has occurred, the BLD and RPE tend to remain anchored to Bruch's membrane over hard drusen as demonstrated in case 7 , so these may be the sites where an ischaemic stimulus would have the most direct effect on the choroid.

Hard drusen, on the other hand, appear to develop independently of AMD. Fused clusters of hard drusen and even the soft drusen derived ultimately from these clusters may appear in middle age and lead to only a focal patch of damage to the RPE. Excessive numbers of small hard drusen at an early age are therefore likely to culminate in so much focal atrophy of the RPE that the diffuse changes never develop. The risk of choroidal neovascularisation appears greatest when diffuse and focal deposits coexist, rather than being a quantitative response to the number and size of soft cluster-derived drusen alone.

We wish to express our appreciation to our Technical Officer, Mrs C. Cassidy, for her valuable contribution to this study. Thanks are due also to the Department of Medical Illustration, Prince of Wales Hospital, Sydney, and to Mr J. Rehak for photographic assistance. This work was supported in part by the Retina Research Foundation, Houston, Texas, and the Gerontology Foundation of Australia.

Key words: Age-related macular degeneration, Choroidal neovascularisation, Hard drusen, Soft drusen. 


\section{REFERENCES}

1. Klein R, Davis MD, Magli YL, Segal P, Klein BEK, Hubbard L. The Wisconsin age-related maculopathy grading system. Ophthalmology 1991;98:1128-34.

2. Bressler SB, Macquarie MG, Bressler NM, Fine SL. The Macular Photocoagulation Study Group. Relationship of drusen and abnormalities of the retinal pigment epithelium to the prognosis of neovascular macular degeneration. Arch Ophthalmol 1990;108:1442-7.

3. Gregor Z, Bird AC, Chisholm IH. Senile disciform macular degeneration in the second eye. Br J Ophthalmol 1977;61: $141-7$.

4. Bressler NM, Bressler SB, West SK, Fine SL, Taylor HR. The grading and prevalence of macular degeneration in Chesapeake Bay watermen. Arch Ophthalmol 1989;107: $847-52$.

5. Klein R, Klein BEK, Linton KLP. Prevalence of age-related maculopathy: the Beaver Dam Eye Study. Ophthalmology 1992;99:933-43.

6. Sarks SH, van Driel D, Maxwell L, Killingsworth M. Softening of drusen and subretinal neovascularisation. Trans Ophthalmol Soc UK 1980;100:414-22.

7. Streicher T, Schmidt K, Dusek J. Hereditäre Drusen der Bruchschen Membran I. Klinische und lichtmikroskopische Beobachtungen. Klin Monatsbl Augenheilk 1982;181: 27-31.

8. Mimoun G, Soubrane G, Coscas G. Macular drusen. Fr J Ophtalmol 1990;13:511-30.

9. Saito Y, Omoto T, Fukuda M. Lobular pattern of choriocapillaris in pre-eclampsia with aldosteronism. Br J Ophthalmol 1990;74:702-3.

10. Sarks SH. Ageing and degeneration in the macular region: a clinico-pathological study. $\mathrm{Br} \mathrm{J}$ Ophthalmol 1976;60: 3224-41.

11. Sarks JP, Sarks SH, Killingsworth M. Evolution of geographic atrophy of the retinal pigment epithelium. Eye 1988; 2:552-77.

12. Sarks SH. Drusen and their relationship to senile macular degeneration. Aust J Ophthalmol 1980;8:117-30.

13. van der Schaft TL, Mooy CM, de Bruijn WC, Oron FG, Mulder PGH, de Jong PTVM. Histologic features of the early stages of age-related macular degeneration: a statistical analysis. Ophthalmology 1992:99:278-86.

14. Tso MOM. Pathogenetic factors of aging macular degeneration. Ophthalmology 1985;92:628-35.

15. Gass JDM. Stereoscopic atlas of macular diseases: diagnosis and treatment. 3rd ed. St Louis: Mosby, 1987:60-4.

16. Green WR, Enger C. Age-related macular degeneration histopathologic studies. The 1992 Lorenz E. Zimmerman Lecture. Ophthalmology 1993:100:1519-35.
17. Chuang MD, Bird AC. The pathogenesis of tears of the retinal pigment epithelium. Am J Ophthalmol 1988;105: 285-90.

18. Casswell AG, Kohen D, Bird AC. Retinal pigment epithelial detachments in the elderly: classification and outcome. Br J Ophthalmol 1985;69:397-403.

19. Gass JDM. Drusen and disciform macular detachment and degeneration. Arch Ophthalmol 1973;90:206-17.

20. Killingsworth MC. Age-related components of Bruch's membrane in the human eye. Graefes Arch Clin Exp Ophthalmol 1987:225:406-12.

21. Oeller J. Ophthalmoskopischer Atlas. Part D. Diseases of the choroid. Wiesbaden: Verlag von JF Bergman, 1899: plate XVII.

22. Pauleikhoff D, Zuels S, Sheraidah GS, Marshall J, Wessing A, Bird AC. Correlation between biochemical composition and fluorescein binding of deposits in Bruch's membrane. Ophthalmology 1992;99:1548-53.

23. Sheraidah G, Steinmetz R, Maguire J, Pauleikhoff D, Marshall J, Bird AC. Correlation between lipids extracted from Bruch's membrane and age. Ophthalmology 1993;100: $47-51$.

24. Pauleikhoff D, Harper CA, Marshall J, Bird AC. Aging changes in Bruch's membrane: a histochemical and morphologic study. Ophthalmology 1990;97:171-8.

25. Weiter JJ, Delori F, Dorey CK. Central sparing in annular macular degeneration. Am J Ophthalmol 1988;106:286-92.

26. Bird AC. Pathogenesis of retinal pigment epithelial detachment in the elderly: the relevance of Bruch's membrane change. Doyne Lecture. Eye 1991;5:1-12.

27. Sunness JS, Johnson MA, Massof RW, Marcus S. Retinal sensitivity over drusen and nondrusen areas: a study using fundus perimetry. Arch Ophthalmol 1988;106:1081-4.

28. Feeney-Burns L, Hilderbrand ES, Eldridge S. Aging human RPE: morphometric analysis of macular, equatorial, and peripheral cells. Invest Ophthalmol Vis Sci 1984;25: 195-200.

29. Green WR, McDonnell PJ, Yeo JH. Pathologic features of senile macular degeneration. Ophthalmology 1985;92: 615-27.

30. Sarks SH. New vessel formation beneath the retinal pigment epithelium in senile eyes. Br J Ophthalmol 1973;57:951-65.

31. Pauleikhoff D, Barondes MJ, Minassian D, Chisholm IH, Bird AC. Drusen as risk factors in age-related macular disease. Am J Ophthalmol 1990;109:38-43.

32. Polverini PJ, Cotran RS, Gimbrone MA Jr, Unanue ER. Activated macrophages induce vascular proliferation. Nature 1977;269:804-6.

33. Killingsworth MC, Sarks JP, Sarks SH. Macrophages related to Bruch's membrane in age-related macular degeneration. Eye 1990;4:613-21. 